\title{
El Antropoceno en Raimon Panikkar: Ecosofía
}

\author{
doi) https://doi.org/10.21814/anthropocenica.3092
}

\begin{abstract}
Resumen: Raimon Panikkar en su amplía producción filosófica estudió también el tema de la ecología, profundamente preocupado por el impacto que la acción humana estaba teniendo en el Planeta Tierra. Su visión filosófica y espiritual le conduce a superar la ecología, tal y como es entendida en la actualidad, y sustituirla por su concepto de Ecosofía, que sería una visión de la sabiduría espiritual de la tierra con características religiosas y espirituales. Aunque Panikkar no abordó la cuestión del Antropoceno en su pensamiento, la Ecosofía puede tener implicaciones para la relectura del concepto. La nueva sensibilidad que Panikkar tiene sobre la Tierra es propuesta en su novenario ecosófico. La aplicación del mismo puede tener consecuencias filosóficas, políticas y espirituales. Todo ello, unido a su visión cosmoteándrica de la realidad, puede conducir a un Antropoceno espiritual, un Antropoceno místico y un Antropoceno religioso, lo que supondría una relectura del propio concepto del Antropoceno.
\end{abstract}

Palabras-clave: Panikkar - Ecosofía - Cosmoteándrico - Antropoceno espiritual
Juan Antonio

Testón Turiel

Instituto Teológico

Compostelano

Universidade de Santiago

de Compostela

Espanha

Dtestonturiel@hotmail.com

Resumo: Panikkar, na sua extensa produção filosófica, também estudou a questão da ecologia, revelando uma preocupação profunda com o impacto que a ação humana estava a ter no planeta Terra. A sua visão filosófica e espiritual levou-o a superar a ecologia tal como é entendida hoje em dia, substituindo-a pelo seu conceito de Ecosofia, que seria uma visão da sabedoria espiritual da terra com características religiosas e espirituais. Apesar de Panikkar não ter abordado a questão do Antropoceno no seu pensamento, a Ecosofia pode ter implicações para a releitura do conceito. A nova sensibilidade que Panikkar tem sobre a Terra é proposta na sua novena ecosófica. A sua aplicação pode ter consequências filosóficas, políticas e espirituais. Tudo isso, juntamente com a sua visão cosmoteândrica da realidade, pode levar a um Antropoceno espiritual, a um Antropoceno místico e a um Antropoceno religioso, o que significaria uma releitura do próprio conceito do Antropoceno.

Palavras-chave: Panikkar - Ecosofia - Cosmoteândrico - Antropoceno espiritual

Abstract: Panikkar, in his extensive philosophical production, also studied the issue of ecology, revealing a deep concern with the impact that human action was having on planet Earth. His philosophical and spiritual vision led him to overcome ecology as it is understood today, replacing it with his concept of Ecosophy, which would be a vision of the spiritual wisdom of the earth with religious and spiritual characteristics. Although Panikkar did not address the issue of the Anthropocene in his work, Ecosophy can have implications for the re-evaluation of the concept. The new sensitivity that Panikkar has about the Earth is proposed in his eco-friendly novena. Its application 
can have philosophical, political and spiritual consequences. All of this, together with his cosmoteandrical view of reality, can lead to a spiritual Anthropocene, a mystical Anthropocene and a religious Anthropocene, which would mean a re-reading of the Anthropocene concept itself.

Keywords: Panikkar - Ecosophy - Cosmotheandric - Spiritual Anthropocene

\section{Introducción}

Desde que en el año 2000 el químico Paul Crutzen enunciara que ya no vivimos en el Holoceno sino en el Antropoceno debido al impacto que la actividad humana está teniendo sobre el planeta (Arias Maldonado, 2020: 19), se han multiplicado las investigaciones de este concepto desde diferentes perspectivas. Por ello, se analizan las consecuencias políticas, económicas, sociales y culturales de la acción del hombre sobre el planeta. Del mismo modo se aborda la investigación del Antropoceno desde las ciencias naturales y sociales, e incluso desde la filosofía y la religión (Trischler, 2017: 54-55). La cuestión del Antropoceno está profundamente unida a la cuestión ecológica, y, por tanto, a la visión que se tiene del hombre y del planeta. El Antropoceno, como ya hemos indicado, tiene consecuencias filosóficas y religiosas. Son numerosos los filósofos que han estudiado la cuestión del Antropoceno desde la perspectiva filosófica y son muchas las aproximaciones que a tal materia se hacen desde este campo. Asimismo, la publicación de la encíclica Laudato Si' del Papa Francisco es un signo que la problemática del trato a la tierra tiene implicaciones religiosas e incluso eclesiales (Francisco, 2015: 181-214).

De entre los filósofos preocupados por el impacto que la tecnología y la actividad humana están generando sobre el planeta hemos de citar a Raimon Panikkar. Su amplia y basta visión filosófica le condujo a analizar las implicaciones de la técnica en la vida humana, en la relación entre los hombres y en su impacto en lo concerniente a la tierra. Para las relaciones con la técnica Panikkar acuña el neologismo, Tecnocronía (Panikkar, 1967: 1-71), y para la dimensión ecológica y su relación con la tierra confecciona el término, Ecosofía (Pérez Prieto \& Meza Rueda, 2046: 101-107). Raimon Panikkar no aborda de forma explícita la cuestión del Antropoceno, pero podemos atisbar en el concepto de Ecosofía ciertas similitudes o implicaciones que pueden completar la cuestión del Antropoceno. Panikkar es plenamente consciente de la impronta que el hombre está dando al planeta tierra, y la problemática que ello supone con respecto a los recursos y al hábitat del propio planeta. El autor cita en diversos lugares la cuestión de la ecología, 


\section{El Antropoceno en Raimon Panikkar: Ecosofía}

especialmente unido a su concepto de Ecosofía, uno de cuyos fundamentos es la teofísica (Panikkar, 2009: 98), otro de los neologismos que acuñó Panikkar en su amplia producción filosófica.

El objetivo de este trabajo de investigación es exponer la visión de la Ecosofía que Panikkar tiene en su pensamiento y las implicaciones y relaciones que tiene con el concepto de Antropoceno. Lo desarrollaremos en tres apartados: en el primero explicitaremos la relación entre los conceptos de ecología y Ecosofía para observar las diferencias entre ambas. En un segundo apartado expondremos la visión cosmoteándrica de la realidad en la que se sustenta la Ecosofía, sustancia en la que encuentra su razón de ser. Y, por último, en el tercer apartado, explicitaremos los nueve puntos de la nueva sensibilidad ecológica panikkariana que tendría implicaciones sociales y políticas.

\section{Ecosofía y Ecología}

Raimon Panikkar trata la cuestión de la ecología en diferentes publicaciones. Es profundamente crítico para con aquellos que consideran a la tierra como un simple objeto, cuyo objetivo es la explotación de sus recursos, y que por tanto hay que procurar que duren lo más posible (Panikkar, 2020: 359). Panikkar, en contraposición a la ecología, y como superación de la misma, propone el neologismo: Ecosofía. Concepto con el que pretende exponer la sabiduría espiritual de la tierra, que va mucho más allá de una ecología entendida como ciencia de la tierra. La ecología nos ha abierto a una nueva relación con la tierra, pero aún no ha llegado a constituir una nueva cosmología (Panikkar, 1999: 107), nos dirá nuestro filósofo. La ecología está inmersa en una noción dualista de la realidad ya que, por un lado, considera el mundo inerte de la realidad material y llena de recursos, y, por otro, el de los seres humanos que están deseosos de explotar esos recursos. La tierra es un objecto pero no se piensa en la posibilidad que pueda ser también un sujeto, como defiende la teoría animista y la Ecosofía (Panikkar, 2016: 307).

Panikkar acuñó el término Ecosofía precisamente en contraposición y para corregir el de ecología, y para, de este modo, superar la concepción que supone la ecología (Testón Turiel, 2020: 376). El autor desea profundizar mucho más. Con el término Ecosofía expresa la sabiduría de la tierra, que es la sabiduría misma de la gestión del hábitat humano (Panikkar, 1994: 115). Con lo que entra de lleno en la cuestión del Antropoceno, un hombre que ha modificado su hábitat, cambiando incluso el planeta, y creando una nueva era geológica. Pero el término Ecosofía está muy alejado del concepto tradicional 


\section{Juan Antonio Téston Turiel}

de ecología y del cuidado de la tierra, es un aspecto mucho más profundo que enraíza con la espiritualidad. Panikkar nos dice con sus propias palabras:

El vocablo Ecosofía quiere indicar la experiencia mística de la materia en general y de la Tierra en particular. La Ecosofía es aquella sabiduría que nos hace sentir que la Tierra es también un sujeto y, más aún, una dimensión constitutiva y definitiva de la realidad... La Ecosofía va mucho más allá de la visión de la Tierra como un ser vivo; nos revela la materia como un factor de lo real tan esencial como la consciencia o lo que solemos llamar lo divino (Panikkar, 2015: 359).

Así, la Ecosofía vendría a ser la sabiduría de la tierra (Meza Rueda, 2010: 137-140), no una visión más o menos convincente de lo que es la tierra, sino más bien la sabiduría de la misma tierra que el hombre recoge cuando entra en comunión con ella, sería afirmar que la tierra es sabia, que posee una sabiduría, y que el ser humano es el portador de esta sabiduría (Panikkar, 1999: 108), y nuestro autor incluso afirma que se debe escuchar a la tierra y tenemos que aprender de ella siendo el hombre su intérprete (Panikkar, 2019:611). Por ello la concepción de la Ecosofía, según Panikkar, está integrada en la espiritualidad y la mística. Con el vocablo Ecosofía Panikkar pretende indicar la experiencia mística de la materia en general y de la tierra en particular. La Ecosofía hace sentir que la tierra no es solamente un objeto sino un sujeto, e incluso una dimensión constitutiva y definitiva de la realidad. Así se revela la materia como un factor esencial de lo real, tanto como la consciencia o lo divino (Panikkar, 2015: 359). Esta visión panikkariana tiene implicaciones de diversa índole en la cuestión del Antropoceno, ya que la Ecosofía dota de sabiduría espiritual al propio planeta, a la realidad material, e implica que tipo de acción podemos ejercer sobre la realidad material, y nos cuestiona sobre cómo ha sido nuestra relación con el entorno hasta el momento presente.

\section{Ecosofía y visión cosmoteándrica}

La Ecosofía panikkariana no se puede entender como una vuelta a un primitivismo más o menos sentimental o irracional, sino más bien a una nueva relación con todas las realidades materiales. Es una integración de todas las experiencias de toda la humanidad y que, en palabras de Panikkar, es la tarea de nuestro tiempo (Panikkar, 2016: 307). Es una llamada de atención del autor para modificar las relaciones entre el hombre y su entorno. Aquí, en la Ecosofía, se encuentra la perfecta conexión con la visión 


\section{El Antropoceno en Raimon Panikkar: Ecosofía}

cosmoteándrica que Raimon Panikkar tiene de toda la realidad (Sepúlveda Pizarro, 2018: 264-268). Y tal materia está compuesta por tres dimensiones: Dios, Hombre y Cosmos (Testón Turel, 2020: 380-382). El principio cosmoteándrico se fórmula afirmando que lo divino, lo humano y lo terreno son tres magnitudes que constituyen todo lo real, es decir toda realidad en cuanto real (Panikkar, 2016: 330). Por ello no podemos hablar de un Hombre separado de Dios y del Cosmos, ya que las tres realidades están inmersas en una misma aventura, la de la existencia y la de la vida, en la que el destino de la Tierra depende del Hombre, y el destino del Hombre depende de Dios (Panikkar, 1994: 45). Es decir que los tres elementos están implicados en la misma realidad y en el mismo fin.

La Ecosofía alude a cómo interactúan la Tierra y el Hombre sin olvidar a Dios. Para Panikkar «un mundo sin hombres no tiene sentido, un Dios sin criaturas dejaría de ser Dios, un Hombre sin Mundo no podría subsistir, y sin Dios, no sería verdaderamente hombre» (Panikkar, 2005: 181). Siguiendo la tradición judeocristiana no se pude amar la tierra sino se ama a Dios sobre todas las cosas, pero también no podemos amar a Dios como Dios si no amamos esta tierra (Panikkar, 2019: 612). Este es el fundamento cosmoteándrico de la Ecosofía en la relación Hombre y Tierra. Para Panikkar la Ecosofía tiene una función reveladora, en la que se desvela que el hombre y su hábitat forman parte de un todo cosmoteándrico (Panikkar, 1999: 108).

\section{La sensibilidad ecosófica}

Lo ya expuesto nos conduce a una visión menos fragmentada de la realidad. Esta nueva actitud no es un retorno sentimental a la naturaleza, sino más bien un descubrimiento de nuestro vínculo advaita y sacramental con la materia (Panikkar, 2016: 308). Panikkar desarrolla esta nueva sensibilidad por medio de nueve puntos y esa sucesión así enunciada constituye la expresión política de su concepción, aunque, para el mismo Panikkar, se trata de una política que supera a la política (Panikkar, 1994: 139).

1. Descapitalizar la cultura. Panikkar ve claro que el dinero, siendo necesario, ha penetrado en todas las relaciones y actividades humanas convirtiéndose en un elemento totalizador. Lo que provoca la dependencia del dinero de todas las actividades humanas, e incluso de la propia cultura. El mundo real no está hecho de productos monetarios y el hecho de tener que pagar absolutamente por todo es signo de una cultura enferma. La monetización de todo valor cultural es la consecuencia natural de la cuantificación de la perspectiva humana (Panikkar, 1994: 139-140). 


\section{Juan Antonio Téston Turiel}

2. Derribar la torre de Babel. La economía mundial concentra los productos cada vez más en un número restringido de organismos, esta tendencia centrípeta es fruto de una concepción mecanicista y cuantitativa de los bienes culturales. Es la denominada civilización tecnocrática que busca tener un único centro, lo que lleva al tecnocentrismo, desechando el etnocentrismo, el antropocentrismo o el teocentrismo. Lo que está claro es que el hombre necesita de un centro, de un punto de referencia y convergencia. En el pensamiento de Panikkar cada uno de los seres humanos pueden encontrar el centro, todo ser humano, toda cultura es un centro de la realidad global. Si desechamos esto caemos en los vaivenes de la moda, el poder, el beneficio y al final en la desesperación. Lo que conlleva la lucha entre los hombres y sobrevivir a costa de los demás. Panikkar propone el pluralismo cultural en el que cada cultura tiene su centro propio. Nosotros somos el centro del universo porque, en cuanto microcosmos, somos un reflejo del todo y estamos abiertos al resto de la realidad, lo que conlleva una interdependencia social y de mercado, en la que necesitamos de los demás (Panikkar, 1994: 140-142).

3. Superar la ideología de los estados nacionales. Panikkar es partidario de elaborar un sistema de relaciones multilaterales que permitan una fructuosa convivencia. $\mathrm{Ni}$ naciones de dimensiones gigantescas ni mini estados nacionales aislados. El objetivo no es transferir la soberanía a los pueblos o a las culturas, no significa transferir la ideología de soberanía autónoma y de absoluta libertad a unidades más bastas o a la humanidad entera. El problema no es político es teológico. Panikkar considera que dos sociedades pueden vivir una relación ontonómica solamente si hay un tercer elemento que los coordina, si forman parte de un todo que es mayor que sus partes, pero que exige el bienestar de las partes para poder ser un todo armónico. Se han derrumbado tanto los imperios como las ideologías de los estados-nación, Panikkar considera que hace falta un nuevo mito (Panikkar, 1994: 143-144).

4. Reconducir la ciencia moderna a sus propios límites. La ciencia moderna ha tenido un éxito sin límites, e incluso ha modificado el modo de pensar del hombre moderno en diferentes campos de las disciplinas científicas. Ha influido en el modo de vida de los diversos sectores de la civilización humana y no podrá ser reconducida a sus límites mediante una imposición externa. Ello solo es posible si se descubre el sentido de la vida humana y la naturaleza de la realidad. Los límites de la ciencia moderna son al mismo tiempo epistemológicos y ontológicos, además de objetivos y subjetivos. Pero la ciencia moderna no es sabiduría, ya que no todo conocimiento es garante de la ciencia. La ciencia moderna no puede equipararse con la intuición de la naturaleza de la realidad (Panikkar, 1994: 144-145). 


\section{El Antropoceno en Raimon Panikkar: Ecosofía}

5. Sustituir la tecnocracia por el arte. En las sociedades actuales el poder ya no reside en Dios, ni es un grupo de personas, sino que está en manos de la moderna tecnología. Así, mientras el artesano tenía necesidad de inspiración, la tecnología moderna ha sustituido el pneuma por el logos, en el sentido de ratio. El científico tiene necesidad de información lo que da lugar a la tecnocracia, y al mismo tiempo el poder ya no está en manos de los políticos, ni de los expertos. La tecnocracia hace imposible al pueblo gestionar el propio destino, ya que la tecnocracia no lo permite, ya que haría necesaria una alta competencia que el pueblo no puede adquirir. Así, de este modo, la tecnocracia transforma a los adultos en niños. El pueblo no sabe lo que le conviene y lo hace incapaz de decidir. De esta manera se hace patente que la tecnocracia está en contradicción con la democracia. Panikkar concibe el arte como aquello que articula la vida y la unifica mediante la creación artística de la persona. El sentido de la vida humana es lograr hacer de cada persona humana una obra de arte. Para conseguirlo necesitamos la participación de todo el universo, desde lo divino, la materia y nuestros semejantes. Cada ser humano debería poder ser capaz de expresarse y construirse a sí mismo en simbiosis positiva con el resto de la Realidad (Panikkar, 1994: 145-147).

6. Superar la democracia con la experiencia de una nueva "kosmología". Panikkar concibe al hombre no como un ser autónomo, sino como una realidad inmersa y entretejida en una red de relaciones. No es un individuo autónomo sino un ser ontónomo, es decir, relacional. Por ello hace falta una nueva antropología basada en una nueva cosmología. A esta última la denomina "kosmología", entendida no tanto como una realidad que es analizada por los científicos sino como la experiencia de una materia que se nos manifiesta o revela. Por ello cada cultura tiene un sentido diferente del cosmos. Una de las problemáticas más evidentes es la que viene dada por los conflictos entre las diferentes kosmologías. Tal disonancia sucede dentro y en torno a nosotros. Dentro de nosotros porque la experiencia contemporánea de la realidad no se siente a gusto con el cosmos, tal y como lo ofrece la visión científica del mundo. Y en torno a nosotros, donde se mezclan diferentes visiones del mundo que no pueden ser gestionadas de modo pacífico si nos dedicamos a confrontarlas entre sí. Panikkar considera que la solución es una nueva cosmología que iría unida a su visión cosmoteándrica (Panikkar, 1994: 147-149).

7. Recuperar el animismo. Panikkar entiende por animismo la experiencia de la vida en continuidad con la naturaleza. Así toda realidad natural es una célula viviente, es parte y reflejo de un todo al mismo tiempo. La filosofía no solo se interesa por el futuro del hombre sino también por el destino del universo entero. En esta visión el tiempo es la vida misma del universo. La existencia individual es la simbiosis entre el Árbol de la Vida 


\section{Juan Antonio Téston Turiel}

y el Ser de los existentes, por ello el sentido de la existencia es participar plenamente en la vida del Universo. El animismo que propone Panikkar es una superación de todas las visiones mecanicistas y racionalistas del mundo. En cada una de las cosas se encierra una chispa de libertad y de vida. El animismo propugna una conexión de toda la realidad, es proponer la interrelacionalidad de todos los fragmentos de la realidad (Panikkar, 1994: 149-150).

8. Hacer la paz con la tierra. La restauración ecológica del mundo no se puede llevar a cabo mientras no lleguemos a considerar la Tierra como nuestro cuerpo y el cuerpo como nuestro Sí, nos dirá Panikkar en una categórica afirmación. Para él, el problema ecológico es de índole teológica y viceversa. De tal modo, en su filosofía es necesario un nuevo pacto, una nueva alianza con la Tierra, que no es un objeto ni de conocimiento ni de codicia, es parte de nosotros mismos y de nuestro "Sí”, por ello se hace necesaria una nueva relación con la misma. No basta con una ecología que ayude una explotación más racional de los recursos de la tierra, sino que se precisa un nuevo paradigma de relación con ella. Hace falta establecer un pacto de paz con la tierra. Una paz que no significa mirada idílica o idealista, ni tampoco una idea estática de la vida. La paz con la tierra excluye la victoria sobre la tierra, su sumisión y su explotación para nuestro uso y consumo, porque tal concordia requiere colaboración, sinergia y nueva consciencia (Panikkar, 1994: 151-152).

9. Recuperar la dimensión divina. Panikkar considera el ateísmo como un modo de teísmo, pero negativo. Politeísmo, monoteísmo y deísmo, pertenecen a una cosmología en decadencia. Y las controversias razón y fe, creyentes y no creyentes han de superarse. Para el autor el misterio divino no se puede encasillar en categorías filosóficas exactas, y la pura trascendencia es una contradicción en términos. Al mismo tiempo, la pura inmanencia es superflua. Si lo divino fuera inmanente sería idéntico a nosotros y por ello un duplicado. Iniciar el discurso sobre lo divino significa aceptar algo irreductible, pero al mismo tiempo relacionado con nosotros. Lo divino es mucho más que un accesorio estético o inteligible. La dimensión divina es la dimensión, irreductible pero no independiente de las otras dos, no es un objeto de materia o conciencia, ya que lo divino carece de sentido sin ellas. Cuando se habla de lo divino resulta inadecuado el antropomorfismo y el cosmomorfismo. Por ello Panikkar propone una visión en que la naturaleza es cosmoteándrica, y en la que las relaciones entre las tres dimensiones, Dios, Hombre y Cosmos, no son dualistas sino trinitarias (Panikkar, 1994: 152-154).

Como ya apuntamos la Ecosofía hunde sus raíces en la concepción espiritual que Panikkar tiene de la tierra. La Ecosofía como toda sabiduría tiene tanto que ver con nuestra 


\section{El Antropoceno en Raimon Panikkar: Ecosofía}

sensibilidad como con nuestro intelecto, ya que el amor a las realidades materiales no es el resultado del orden de nuestro intelecto, sino que es un movimiento espontaneo de nuestro ser. Algunos pretenden ver el orden material únicamente como un ámbito para extraer recursos, y no como una realidad viva, en cambio para Panikkar la tierra tiene una vida propia que no es la vegetal ni la animal (Panikkar, 2019: 612).

\section{Conclusiones}

En el pensamiento de Raimon Panikkar la visión ecológica de la relación hombre y cosmos no ofrece una visión certera de la realidad, ya que explica la relación como una visión dual y de nexo entre dos seres. Panikkar ofrece una visión de la Ecosofía que supera el anterior planteamiento, exponiendo la Ecosofía como la sabiduría espiritual de la Tierra, en la que hay que integrar la espiritualidad y la mística. Es una nueva visión de la Tierra y del Hombre, una nueva antropología y kosmología. Con el vocablo Ecosofía Panikkar indica la experiencia mística de la materia en general y de la tierra en particular. La Ecosofía hace percibir que la tierra no es solamente un objeto sino un sujeto, e incluso una dimensión constitutiva y definitiva de la realidad. La Ecosofía hace ver la tierra en relación a lo humano y a lo divino, lo que conduce a la visión cosmoteándrica de Panikkar.

La visión cosmoteándrica de Panikkar es mucho más que una visión filosófica, es una verdadera concepción espiritual de la realidad y de todo lo que existe. Aplicada a la concepción del Antropoceno supondría que el hombre tiene una relación especial con su hábitat, con el mundo que le rodea de modo que ambos se necesitan, como diría Panikkar para hacer entender que hay una interdependencia entre todo lo que existe, lo que podría llevar a formular que hay un Antropoceno espiritual. La acción del hombre sobre el planeta es una acción espiritual, no una simple acción material de cambio de la realidad. La visión cosmoteándrica y ecosófica de Panikkar podría resituar la cuestión del Antropoceno no únicamente como una modificación de lo material, sino verlo desde una interrelacionalidad entre el Hombre, el Cosmos y Dios.

Su novenario sobre la Ecosofía tiene consecuencias antropológicas, ecológicas y políticas, y pueden ser aplicadas a la cuestión del Antropoceno. Panikkar es partidario de superar una visión de la sociedad monetaria y economicista en la que todo se compra y se vende, en la que todo está cuantificado y medible monetariamente, incluso el propio hombre. Todo lo cual lleva consigo la lucha entre los hombres e incluso sobrevivir a costa de los demás. Panikkar propone una suerte de pluralismo cultural, sistema en el que cada 


\section{Juan Antonio Téston Turiel}

cultura y cada ser humano tienen su centro propio. Al mismo tiempo cada ser humano es el centro del universo porque en cuanto microcosmos es un reflejo del todo y está abierto al resto de la realidad, lo que conlleva una interdependencia social y de mercado, en la que necesitamos de los demás. Lo que tiene como consecuencia superar la concepción de los estados nación, y ello se puede lograr creando nuevos ámbitos de relación entre los pueblos. Para el autor no se trata de una cuestión política sino de un asunto teológico. Por su parte la ciencia moderna, causante, en gran parte, de la técnica que ha propiciado el cambio del planeta y la llegada del Antropoceno, debe de recuperar sus límites para que los cambios no sean irreversibles, y ello solo es posible para Panikkar si se recupera el sentido de la vida y la verdadera naturaleza de la realidad. En el pensamiento de Panikkar lo que captamos por los sentidos o lo que nos dice la ciencia no aclara la realidad en toda su verdad, por tanto la acción del hombre sobre el planeta no explica totalmente quien es el hombre ni lo que es el planeta. Solamente si el hombre encuentra el sentido de su propia vida podrá saber cuál es el sentido de su acción sobre la Tierra y, del mismo modo, si la realidad es mucho más que lo que captamos por los sentidos, hemos de intuir qué tipo de realidad y de planeta estamos confeccionado al modificarlo por la acción humana.

Raimon Panikkar es partidario de sustituir la tecnocracia por el arte. Para el autor el sentido de la vida humana es lograr hacer de cada persona humana una obra de arte. Y ello no se podrá conseguir sin la participación de todo el universo, lo divino, la materia y nuestros semejantes. Cada ser humano debe poder ser capaz de expresarse y construirse a sí mismo en simbiosis positiva con el resto de la Realidad. Todo ello solamente se puede lograr desde una nueva antropología, en la que el Hombre es concebido no como un ser autónomo sino como una ser ontónomo, es decir, inmerso en un mar de relaciones, en las que incluye la relación con el cosmos, por ello es partidario de una nueva cosmología, una nueva experiencia de la realidad. Pero una realidad que no es la captada por los científicos, sino una realidad que se nos manifiesta o revela a nosotros. Así es partidario de recuperar el animismo, entendido éste como la experiencia de la vida en continuidad con la naturaleza y, por ello, propone la interrelacionalidad de todos los fragmentos de la realidad. Todo lo cual es el preámbulo de su visión cosmoteándrica, en la que la tierra es considerada como parte de nosotros mismos. Panikkar considera necesario establecer un pacto de paz con la tierra. Asimismo, es necesario recuperar la dimensión divina, que no puede ser independiente de la dimensión humana y de la dimensión cósmica. Por ello, Panikkar propone una visión en que la naturaleza es cosmoteándrica, y en la que las relaciones entre las tres dimensiones, Dios, Hombre y Cosmos, no es dualista sino trinitaria. 


\section{El Antropoceno en Raimon Panikkar: Ecosofía}

La visión cosmoteándrica de Panikkar ayuda a resituar en su justa medida la relación que el hombre debe de tener con la naturaleza, y cuál es la presencia de lo humano y de lo divino en la misma. La cuestión del Antropoceno a la luz de la filosofía de Raimon Panikkar no se puede ver únicamente como una visión dual y de relación entre lo humano y el planeta tierra, hay que tener en cuenta la dimensión divina y lo espiritual, por ello tal perspectiva exige una visión trinitaria. Esta nueva percepción permitiría un trato diferente de la tierra por parte del hombre y tendría como consecuencia el poder hablar de un Antropoceno espiritual, un Antropoceno místico y un Antropoceno religioso.

\section{Bibliografía}

Arias Maldonado, M. (2018). Antropoceno. La política en la era humana, Barcelona: Editorial Taurus.

Arias Maldonado, M. (2020). Antropoceno. Revista Universitaria de Cultura, 23: pp. 1623.

Francisco (2015). Carta Encíclica. Laudato Si. Sobre el cuidado de la casa común, Madrid: San Pablo.

Meza Rueda, J. L. (2009). La Antropología de Raimon Panikkar y su contribución a la antropología teológica cristiana, Bogotá: Pontificia Universidad Javeriana.

Meza Rueda, J. L. (2010). Ecosofía: otra manera de comprender y vivir la relación hombremundo. Cuestiones Teológicas, 37: pp. 119-144.

Panikkar, R. (1967). Técnica y tiempo, Buenos Aires: Editorial Columba.

Panikkar, R. (1994). Ecosofía. Para una espiritualidad de la tierra, Madrid: Editorial San Pablo.

Panikkar, R. (1999). El espíritu de la política. Homo politicus, Barcelona: Ediciones Península. 


\section{Juan Antonio Téston Turiel}

Panikkar, R. (2005). El Silencio del Buddha. Una introducción al ateísmo religioso, Madrid: Ediciones Siruela.

Panikkar, R. (2009). La puerta estrecha del conocimiento. Sentidos, Razón y Fe, Madrid: Herder.

Panikkar, R. (2015). La experiencia de la Vida. La mística. En: Panikkar, R. (2015). Obras Completas, I. Mística y espiritualidad, 1. Mística, plenitud de Vida (pp. 193-416), Barcelona: Herder.

Panikkar, R. (2016). Colligite Fragmenta. Por una integración de la realidad. En: Panikkar, R. (2016), Obras Completas, VIII. Visión trinitaria y cosmoteándrica: Dios-HombreCosmos (pp.237-363). Barcelona: Herder.

Panikkar, R. (2019). La dimensión divina. En: Panikkar, R. (2019). Obras Completas, X. Filosofía y teología, 1. El ritmo del Ser. Las Gifford Lectures (pp. 553-633). Barcelona: Herder.

Pérez Prieto, V. \& Meza Rueda, J. L. (2016). Diccionario Panikkariano, Barcelona: Herder.

Sepúlveda Pizarro, J. (2018). Ecosofía: hacia una comprensión de la sabiduría de la tierra desde la noción de ritmo del ser de Raimon Panikkar. Ilu, 23: pp. 263-278.

Testón Turiel, J.A. (2020), El itinerario intelectual de Raimon Panikkar (1919-2010): teología, filosofía y espiritualidad. Compostellanum, 65: pp. 349-395.

Trischler H. (2017). El Antropoceno, ¿un concepto geológico o cultural, o ambos? Desacatos, 54: pp. 40-57. 
El Antropoceno en Raimon Panikkar: Ecosofía

Para citar:

Téston Turiel, J. (2020). El Antropoceno en Raimon Panikkar: Ecosofía. Anthropocenica. Revista de Estudos do Antropoceno e Ecocrítica 1: pp. 41-53. 